\title{
BENJAMIN CONSTANT: LA DEFENSA DE LA LIBERTAD DE EXPRESION
}

«Durante cuarenta años he defendido el mismo principio, libertad en todo, en religión, en filosofía, en literatura, en industria y en política $\gg^{1}$. Así resume Benjamin Constant su pensamiento en una de sus últimas obras, Mélanges de littérature et de politique, publicada en 1829, un año antes de su muerte. A pesar de que su carrera política discurre por un trazado difícil y a veces contradictorio, complejo y agitado, como las circunstancias históricas de la Francia de su época, es cierto que el pragmatismo de sus propuestas encierra siempre el mismo ideario liberal, tenazmente sostenido bajo el Directorio, el Consulado, el Imperio, la Restauración, los Cien Días, la monarquía constitucional y los prolegómenos de la Revolución de julio de 1830.

«Liberad en todo», una afirmación que hace de Constant el defensor modélico de las llamadas libertades negativas, de esas libertades que él asimila a la «libertad de los modernos $»^{2}$, imprescindibles en el nuevo tipo de sociedad que se está construyendo trabajosamente tras el hundimiento definitivo del Antiguo Régimen y los horrores de la Revolución.

1 Mélanges de littérature et de politique, en Oeuvres, París, Gallimard, 1957, p. 801.

2 Véase De la liberté des anciens comparée à celle des modernes, París, 1819. Hay traducción española en B. CONSTANT, Escritos políticos, Madrid, Centro de Estudios Constitucionales, 1989 , pp. 257-285. 
Una libertad que hay que rodear, sin embargo, de todo tipo de garantías que permitan su disfrute en el espacio que le es propio y marquen, definitiva y tajantemente, los límites de la autoridad política, dominada siempre por su tendencia natural a expandirse más allá de sus competencias y a ejercerlas de forma arbitraria. Y entre estas garantías la primera es la libertad de prensa, sin la cual «todas las barreras civiles, políticas y judiciales se convierten en ilusorias» ${ }^{3}$.

La batalla por la libertad de expresión es la más larga y la más recurrente de cuantas batallas políticas emprende Constant, tanto en su faceta de pensador y publicista como en la de político activo desde su cargo de Diputado de la oposición en los diferentes gobiernos de la Restauración.

Incluso en sus primeras obras, publicadas durante el Directorio, las críticas que hace Constant a la prensa, por fomentar la desestabilización de un régimen que representa para él la única vía para salvaguardar los logros de la Revolución, no pretenden nunca la imposición de censura alguna, y en ellas reconoce ya que «los periódicos son, quizá, el más eficaz, y a veces el único, recurso contra los actos de opresión individual, inseparables de cualquier gobierno administrado por los hombres» ${ }^{4}$. Y la primitiva redacción de sus Principes de politique, fechada en los años de exilio voluntario, tras su ruptura con Napoleón, contiene ya varios capítulos con las líneas principales de su argumentación, que mantendrá inalterables en el futuro. Sin embargo, serán los proyectos de ley para el restablecimiento de la censura, auspiciados por los ministros de Luis XVIII, los que le llevarán, una y otra vez, a levantar su voz en favor de la libertad de prensa, tanto desde su escaño en la Cámara como desde las páginas de sus folletos o de los periódicos de la época.

Escribir sobre el derecho a la libertad de expresión con la memoria aún viva de los excesos cometidos por la Revolución, obliga a Constant a abordar la cuestión desde una doble perspectiva histórica y política. Si la Revolución fue inevitable, el Terror no era necesario para llevarla a cabo. Pero a los crímenes del Terror en nada contribuyó la amplia difusión y discusión de las ideas que le precedió. Fue precisamente la imposibilidad de debatir públicamente los actos vergonzosos de un régimen tiránico lo que facilitó su impunidad y propició una literatura panfletaria mendaz, exagerada y cruel, tanto al servicio del poder como de los cenáculos clandestinos de la oposición.

El conocimiento público, el debate y la crítica de los actos del gobierno es, para Constant, la única vía para frenar y remediar los desmanes en que pueda incurrir el poder político. Y en las sociedades modernas, masificadas, atareadas en sus asuntos privados, alejadas de los centros de decisión

${ }^{3}$ Vid. infra, p.

+ Des réactions politiques, París, 1797. La cita corresponde a la edición incluida en el Cours de politique constitutionelle, París, 1861, vol. II, p. 94. 
política, formando naciones de gran extensión geográfica y elevado número de habitantes, ese tipo de publicidad pasa necesariamente por la prensa. Los periódicos se han convertido así en un elemento imprescindible, en la principal garantía de las libertades individuales, porque ningún otro medio de reclamación resulta eficaz si no va acompañado de la difusión que asegura la prensa.

Y también la libertad política, la libertad positiva, precisa de estos modernos medios de comunicación. El sistema representativo, la única forma de participación política viable para grandes asociaciones humanas, obliga a delegar la soberanía en unos representantes encargados de hacer la ley. Pero esta delegación es insuficiente para asegurar la defensa de los intereses de los representados. Cuando nombramos un administrador de nuestros bienes - dice Constant en La libertad de los antiguos comparada con la de los modernos - debemos vigilarle y controlarle para que no nos engañe. La opinión pública ejerce ese control sobre sus representantes políticos: «la opinión pública —afirma Constant- es la vida de los Estados», y esa opinión sólo se configura a través de la prensa.

A través de la prensa se hace efectiva también la división de funciones propia de una monarquía constitucional, que nuestro autor fue el primero en definir nítidamente. El rey, como árbitro moderador de los distintos poderes del Estado, carece de responsabilidad política, pero los ministros deben dar cuenta de todos y cada uno de sus actos como gobernantes. Una responsabilidad que les debe exigir, en primer lugar, la opinión pública a través del debate de sus decisiones canalizado a través de la libre expresión de los gobernados en todo tipo de publicaciones, incluida la prensa periódica.

A este enfoque tan moderno y tan actual del papel que deben cumplir lo que hoy llamamos medios de comunicación social, Constant añade también el punto de vista del poder político, inclinado siempre a obstaculizar una completa libertad de expresión con leyes represoras, en la creencia de que se defiende a sí mismo al impedir las críticas de mayor alcance. Para Constant, es la propia dignidad y credibilidad del poder la que exige también la eliminación de cualquier censura. Un gobierno que puede prohibir, ampara todo lo que permite; un gobierno que puede silenciar a sus adversarios, debilita los argumentos de sus defensores; un gobierno que cierra los cauces legales a la libre opinión, no sólo favorece los rumores y la opinión clandestina, sino que impide distinguir la verdad de la calumnia, otorgando a ésta la verosimilitud de las afirmaciones que no pueden ser rebatidas.

Hay que mencionar, por último, la propuesta de Constant frente a la espinosa cuestión del alcance y los límites de esa libertad de prensa. La libertad total que él reclama no pasa, evidentemente, por el insulto, la difamación y la calumnia. $\mathrm{Ni}$ atañe tampoco a la vida privada de las personas, aunque ejerzan cargos públicos. La línea de demarcación está clara: 
con respecto a los particulares, sólo los actos delictivos, una vez llevados ante un Tribunal, pueden ser objeto de especulación pública; por lo que se refiere a los servidores del Estado, sólo sus actuaciones públicas pueden merecer la atención de la prensa. El escritor o periodista que divulgue asuntos pertenecientes a la vida privada de las personas será inmediatamente castigado. La sola mención del nombre del interesado se considerará prueba suficiente del delito, sin necesidad de instruir largos sumarios.

Hoy no sería posible, quizá, zanjar el problema de forma tan sencilla, porque toda una serie de nuevos factores sociológicos, económicos y hasta tecnológicos dificultan tan tajante separación entre lo público y lo privado. Sigue vigente, sin embargo, la recomendación que hace Constant en uno de sus múltiples escritos sobre estas cuestiones: «Por lo que respecta a los ataques que no sean graves, más vale habituarse a las inclemencias del tiempo que vivir en un subterráneo. Cuando los periódicos son libres como en Inglaterra los ciudadanos se endurecen. La menor desaprobación, el menor sarcasmo, no les causa heridas mortales. Para rechazar las acusaciones odiosas tienen los tribunales; para garantizar su amor propio tienen la indiferencia; en primer lugar la del público, que es muy grande, mucho más de lo que creen, y después la suya, que les viene por costumbre» ${ }^{5}$.

Los textos que se incluyen en esta selección corresponden a tres momentos diferentes y a tres aspectos distintos de la libertad de expresión: el derecho a manifestar por escrito toda clase de ideas y opiniones, la libertad de imprenta para obras de pequeña extensión y gran difusión, y la libertad de prensa propiamente dicha. El primero de dichos textos pertenece a los capítulos 3 y 4 del libro VII de la primera redacción de los Principes de Politique, que Constant no llegó a publicar y que sirvió de base a su obra del mismo título aparecida en 1815. Los manuscritos originales han sido editados y anotados por Etienne Hofmann, bajo el título Les «Principes de politique» de Benjamin Constant, Genève, Droz, 1980. El segundo recoge la primera parte de un folleto de Constant aparecido en 1814, en respuesta al discurso del ministro del Interior, Montesquiou, defendiendo una ley que restablecía la censura para escritos inferiores a veinte páginas. El tercero es el texto íntegro de un artículo de Constant aparecido en el periódico $\mathrm{La}$ Minerve Française en febrero de 1820. Los tres textos están inéditos en castellano y su traducción se ha hecho especialmente para la REIS.

María Luisa SÁnchez-Mejía

'De la liberté des brochures, des panphlets et des journaux, París, 1814. Hay traducción castellana en B. CONSTANT, Escritos politicos, op. cit., pp. 207-239. 